\title{
Zonisamide (CI-912) and Cognition: Results from Preliminary Study
}

\author{
Stanley Berent, J. Chris Sackellares, Bruno Giordani, John G. Wagner, \\ Peter D. Donofrio, and Bassel Abou-Khalil \\ Departments of Neurology and Psychiatry and College of Pharmacy, University of Michigan Medical Center, \\ Ann Arbor, Michigan, U.S.A.
}

\begin{abstract}
Summary: Nine patients with refractory partial seizures were evaluated in a pilot study of a new anticonvulsant compound, zonisamide (1,2-benzisoxazole-3-methanesulfonamide; CI-912). Cognitive functioning was evaluated prior to treatment with zonisamide and repeated after 12 and 24 weeks of treatment with zonisamide. At minimum steady-state plasma concentrations $>30 \mu \mathrm{g} / \mathrm{ml}$, zonisamide appeared to affect specific cognitive functions such as acquisition and consolidation of new information. Previously learned material, such as vocabulary,
\end{abstract}

The results of initial clinical trials have indicated that zonisamide (1,2-benzisoxazole-3-methanesulfonamide; CI-912) may be effective in controlling partial seizures in humans (Sackellares et al., 1985; Wilensky et al., 1985). The anticonvulsant properties of zonisamide were discovered through extensive testing of a variety of sulfonamide compounds (Masuda et al., 1980). Anticonvulsant properties of zonisamide have been demonstrated in several animal models, including maximal electroshock seizures, maximal pentylenetetrazol-induced seizures, and kindling (Masuda et al., 1980; Kamei et al., 1981). The compound was shown to suppress focal spiking and spread of secondary generalized seizures in experimental animals (Ito et al., 1980). Together these works indicated that the anticonvulsant profile of zonisamide was similar to that of phenytoin or carbamazepine.

Masuda and co-workers (1979) studied the rela-

Received January 30, 1986; revision received October 16, 1986.

Address correspondence and reprint requests to Dr. S. Berent at CFOB B4961-0704, University of Michigan Hospitals, Ann Arbor, MI 48109-0704, U.S.A. and psychomotor performance were not affected. Verbal learning was affected, while visual-perceptual learning was unimpaired. These cognitive effects were observed in the absence of the usual clinical signs and symptoms of toxicity. A linear relationship was found between impairment of cognitive abilities and the minimum plasma concentration $(r=-0.73 ; p<0.05)$. Findings also suggest the development of tolerance to the adverse cognitive effects. Key Words: Antiepileptic drugs-Cognition-Epilepsy-Neuropsychology - Zonisamide. tionship between the plasma concentrations of zonisamide and anticonvulsant effects and impaired motor function in animals. Based on comparison with phenytoin, phenobarbital, and carbamazepine in these animal paradigms, the authors predicted that zonisamide would be effective clinically at plasma concentrations between 10 and $70 \mu \mathrm{g} / \mathrm{ml}$.

We previously described the single- and multipledose pharmacokinetics of zonisamide in patients receiving other antiepileptic drugs and reported preliminary evidence of the safety and efficacy of zonisamide in controlling medically refractory partial seizures in humans (Wagner et al., 1984; Sackellares et al., 1985). We found that in most patients, seizure frequency was reduced after substituting zonisamide for a standard antiepileptic drug. Doserelated, reversible central nervous system and gastrointestinal side effects were observed, but most patients tolerated doses between 5.2 and $12.5 \mathrm{mg} /$ $\mathrm{kg} /$ day. Clinically significant antiepileptic effects were observed with plasma concentrations between 15 and $20 \mu \mathrm{g} / \mathrm{ml}$. Signs of clinical toxicity appeared to occur primarily when plasma concentrations exceeded $40 \mu \mathrm{g} / \mathrm{ml}$.

A number of investigators have demonstrated 
effects of antiepileptic drugs on cognitive functions (Matthews et al., 1975; Macleod et al., 1978; Thompson and Trimble 1980; Giordani et al., 1983). However, Trimble (1981) has emphasized difficulty of separating antiepileptic drug effects on memory from the effects of seizures on learning and memory. The cognitive side effects, moreover, might vary from one drug to another. Both Trimble and Thompson have argued for the careful measurement of behavior that is in direct relation to a specific anticonvulsant compound.

In the present study, we evaluated the effects of zonisamide on neuropsychological performance. Several aspects of behavior were measured to determine those abilities that tend to be vulnerable to drug effects as well as those that are more resistant to drug effects. Measures were chosen to reflect attention, concentration, sustained effort, personal and current information, verbal and visual-perceptual learning, and immediate as well as delayed recall of learned materials.

\section{METHODS}

Six men and five women of nonchildbearing potential entered this study. All patients were between 19 and 50 years of age and had at least four partial seizures per month in spite of therapeutic plasma levels of two or three standard antiepileptic drugs. Patients with more than four generalized tonic-clonic seizures in the three months prior to the study were excluded. Patients with other significant medical or psychiatric illnesses, with progressive neurologic disorders, or those with a history of status epilepticus were not eligible for this study. Informed written consent was obtained in each case.

On entering the study, complete neurologic and general physical examinations, electrocardiogram, EEG, complete blood count, blood chemistry profile, plasma anticonvulsant levels, and urinalysis were obtained for each patient. Seizures were classified according to the Revised International Classification of Epileptic Seizures (Dreifuss et al., 1981). One patient withdrew from the study before receiving zonisamide and another patient was withdrawn by the investigator before completing all intended neuropsychological evaluations. This latter individual was withdrawn because of an abrupt increase in seizure activity. The nine patients completing the clinical trial are included in the present report. The protocol employed in the clinical trial has been reported previously (Sackellares et al., 1985). A summary of the study protocol is presented in Table 1.
TABLE 1. Summary of experimental protocol

\begin{tabular}{|c|c|c|}
\hline Study phase & Treatment & Duration \\
\hline \multicolumn{3}{|l|}{ 1. Eligibility } \\
\hline 2. Baseline & $\begin{array}{c}\text { Two or three standard } \\
\text { antiepileptic drugs }\end{array}$ & 8 weeks \\
\hline \multicolumn{3}{|c|}{$\begin{array}{l}\text { 3. Neuropsychological } \\
\text { examination } \\
\text { (session } 1 \text { ) }\end{array}$} \\
\hline $\begin{array}{l}\text { 4. Zonisamide } \\
\text { treatment }\end{array}$ & $\begin{array}{l}\text { Single-dose kinetic study } \\
\text { (1 week), multiple-dose } \\
\text { study (I week), } \\
\text { withdrawal of one } \\
\text { baseline drug }(\sim 10 \\
\text { days), continuation of } \\
\text { zonisamide treatment }\end{array}$ & 12 weeks \\
\hline \multicolumn{3}{|l|}{$\begin{array}{l}\text { 5. Neuropsychological } \\
\text { examination } \\
\text { (session } 2)\end{array}$} \\
\hline $\begin{array}{l}\text { 6. Outpatient follow- } \\
\text { on treatment }\end{array}$ & & 12 weeks \\
\hline $\begin{array}{l}\text { 7. Neuropsychological } \\
\text { examination } \\
\text { (session 3) }\end{array}$ & & \\
\hline
\end{tabular}

The study design included an 8-week baseline period during which each patient continued receiving either two or three standard antiepileptic drugs. These included phenytoin, phenobarbital, carbamazepine, primidone, and valproic acid. Details concerning individual doses and other clinical information have been provided by us in an earlier report (Sackellares et al., 1985). Following the baseline period, a single-dose pharmacokinetic study was performed. After completion of this pharmacokinetic study, zonisamide was administered orally every $12 \mathrm{~h}$. The initial dose for each patient was based on single-dose kinetic parameters calculated for that patient. On the 8th day of zonisamide treatment, each patient was admitted to the University of Michigan Clinical Research Center for $\sim 10$ days. One baseline antiepileptic drug was withdrawn and blood was sampled each day and later analyzed for all anticonvulsant drugs. Doses of zonisamide were adjusted to achieve a plasma concentration of $15-40 \mu \mathrm{g} / \mathrm{ml}$ (or reduced, when necessary, to eliminate side effects). Once the plasma concentration of the drug withdrawn fell to $<15 \%$ of the initial level, the patient was discharged from the hospital and evaluated weekly for 4 weeks, then every 2 weeks for the remainder of the 12-week treatment. Clinical and laboratory examinations were identical to those done during the baseline period. Following the initial drug withdrawal, no further drug was eliminated.

Neuropsychological examinations were administered at the end of the 8-week pre-zonisamide baseline period (session 1), and at the end of the 12th week of zonisamide treatment (session 2). Patients 
were then continued in a follow-on study of zonisamide and were again evaluated with these neuropsychological procedures at the end of 3 months into the follow-on period (session 3). All psychometric tasks were administered by trained neuropsychological technicians. The technicians were not informed about drug or other clinical status of the patients except as required for safe clinical management of the individual.

The neuropsychological tests used in this study are listed and described in Table 2. The specific behavioral tasks were chosen because of their established validity and reliability, including construct and face validity. When possible, tests with alternative forms were used to minimize practice effects. Psychological tests for which the effects of practices are fairly well understood also were employed. For example, the Wechsler Memory Scale (WMS) was selected because of its alternative forms. The Wechsler Adult Intelligence Scale (WAIS-R) was employed, because of its extensive use in studies with test-retest designs (Matarazzo, 1974). Other tasks were chosen because they were easily standardized in administration.

\section{RESULTS}

The WMS yields a normalized, age-corrected memory quotient (MQ) which represents the com- bination of performance on the various subscales which make up this instrument. Figure 1 presents the change in MQ that occurred for each patient between the end of the baseline period and the end of the first 12-week zonisamide treatment period. Over this 12-week interval between test sessions, a substantial decline (up to $25 \%$ in some cases) in MQ was observed in every patient (mean change = -15.1 .

Figure 2 illustrates the change in MQ that occurred between the second test session, performed after 12 weeks of zonisamide therapy, and the third test session, performed after 24 weeks of zonisamide therapy.

In contrast to the first treatment period, the decline in MQ substantially receded for each patient at the time of this third testing. There was a movement in scores to within an average of five points from the original average $M Q$ for the group of patients under study (mean change between sessions 2 and $3=10.1$ ).

The average MQ score for each test session is presented in Figure 3.

The overall mean MQ for session 2 was significantly different from the mean MQ at baseline $(p<$ $0.001)$. Not only was there a change in average MQ between the sessions, but the mean plasma level for zonisamide was higher (but not significantly different) in session $2(31.2 \mu \mathrm{g} / \mathrm{ml})$ than in session 3

TABLE 2. List and brief description of neuropsychological instruments employed

\begin{tabular}{|c|c|}
\hline Test instrument & Description \\
\hline 1. Wechsler Memory Scale (WMS) (Wechsler, 1945) & $\begin{array}{l}\text { A standardized and commercially available test of attention, learning, } \\
\text { and memory. The score (MQ) is a summary of performance on } \\
\text { seven subtests. }\end{array}$ \\
\hline $\begin{array}{l}\text { 2. Wechsler Adult Intelligence Scale-Revised (WAIS-R), } \\
\text { selected subtests (Wechsler, 1981) }\end{array}$ & $\begin{array}{l}\text { The Vocabulary subtest of the WAIS-R consists of words presented in } \\
\text { increasing level of difficulty for the patient to define. Arithmetic is } \\
\text { a series of arithmetic problems of varying levels of difficulty. Digit } \\
\text { Symbol is a psychomotor task in which the person must translate } \\
\text { numbers to symbols in a timed format. }\end{array}$ \\
\hline 3. Reaction Time (RT)-Simple and Choice & $\begin{array}{l}\text { A Lafayette Instruments model } 63014 \text { multichoice Reaction Timer was } \\
\text { used. Simple RT consists of subject responding to a red cue light as } \\
\text { quickly as possible by pressing a response key with the dominant } \\
\text { index finger. Twenty trials were administered, with subject"s score } \\
\text { the mean in milliseconds over the last } 10 \text { trials. The choice } \\
\text { procedure consisted of } 30 \text { trials with subject being asked to respond } \\
\text { only to trials in which a red stimulus cue appeared. "Error" trials } \\
\text { were interspersed at set intervals. Subject's score was the average } \\
\text { RT over the } 10 \text { test trials. A "warning" white cue light preceded the } \\
\text { stimulus light by } 1 \text { s on all trials. }\end{array}$ \\
\hline 4. Grip Strength (Boll, 1981) & $\begin{array}{l}\text { A standard, commercially available dynamometer was used to } \\
\text { measure the individual's strength of grip (in kg pressure) for each } \\
\text { hand. }\end{array}$ \\
\hline 5. Finger Tapping (Boll, 1981) & $\begin{array}{l}\text { A standardized procedure was used to quantitate the person's speed } \\
\text { of oscillation of the index finger of each hand (measured in taps } / \mathrm{min} \text { ). }\end{array}$ \\
\hline 6. Rod-and-Frame (Witkin et al., 1974) & $\begin{array}{l}\text { The apparatus yields a score, in degrees error from true vertical, of } \\
\text { the patient's ability to set a target rod to true vertical. }\end{array}$ \\
\hline 7. Grooved Peg Board & $\begin{array}{l}\text { Yields average time (in s) to place a set number of pegs in a standard } \\
\text { test board. }\end{array}$ \\
\hline
\end{tabular}




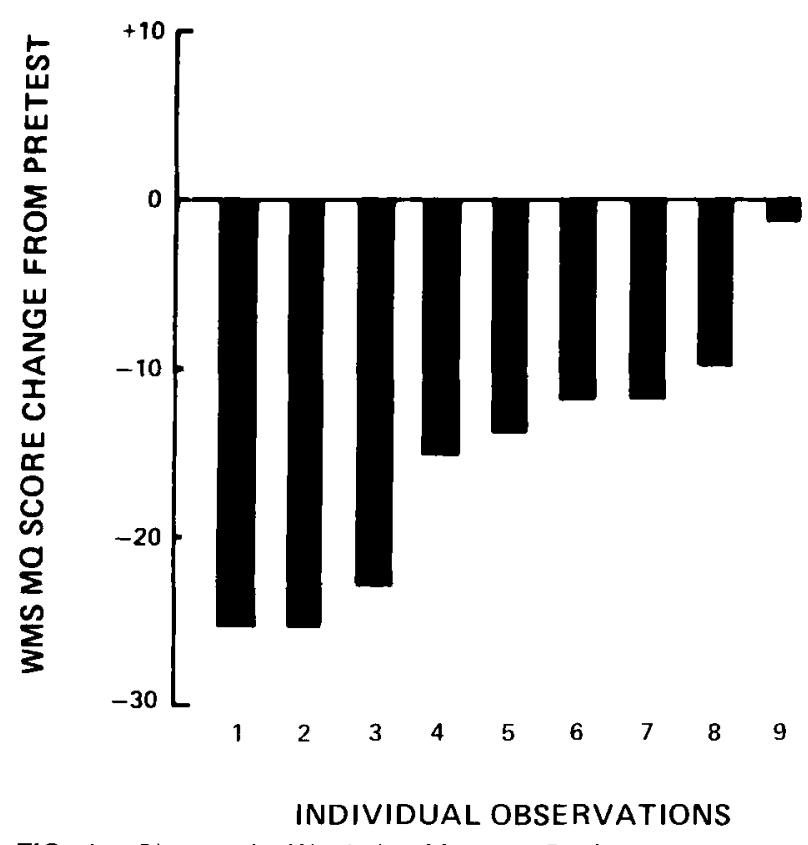

FIG. 1. Change in Wechsler Memory Scale memory quotient (WMS-MQ) for each patient between session 1 (baseline) and session 2 (end of 12-week treatment period).

$(26.5 \mu \mathrm{g} / \mathrm{ml})$. This observation suggests a relationship between plasma level of zonisamide and measured cognitive function. Figure 4 reflects the very strong linear relationship that exists between the observed change in MQ and plasma levels of zonisamide at the time of session 2 (Pearson $r=-0.73$, $\mathrm{p}<0.05$ ).

Interestingly, the very strong relationship between plasma concentration of zonisamide and MQ

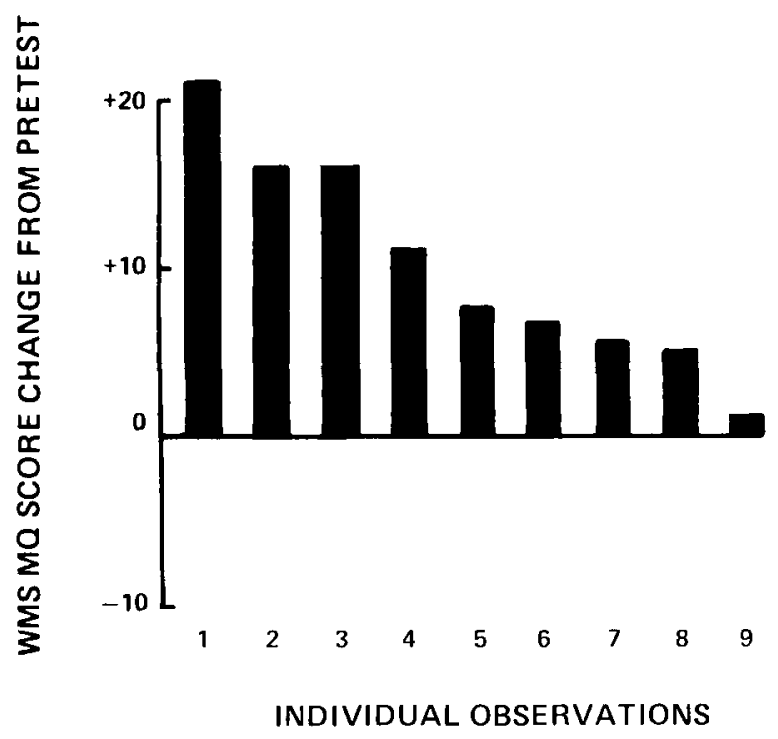

FIG. 2. Change in Wechsler Memory Scale memory quotient (WMS-MQ) for each patient between session 2 and session 3 (end of 12-week follow-on period).

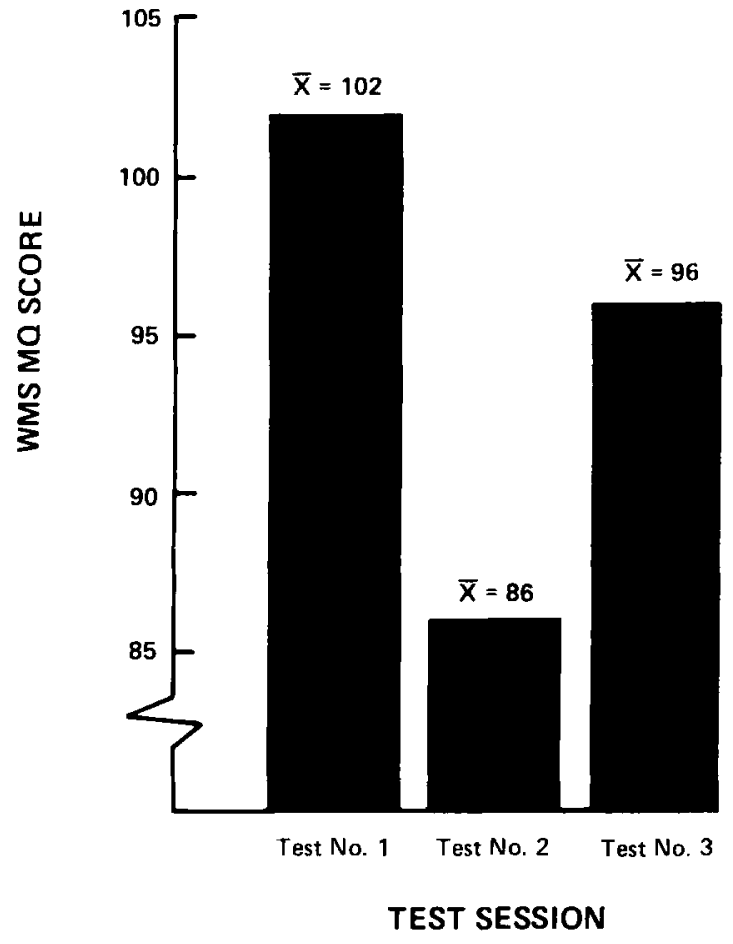

FIG. 3. Average Wechsler Memory Scale memory quotient (WMS-MQ) for each test session.

observed at the time of the second testing declined substantially by the time of the third test session. The relationship between the change in MQ between session 3 and the baseline, session 1 , was $r$ $=-0.21(\mathrm{p}=\mathrm{NS})$.

Table 3 summarizes performance on the behavior test measures and the various subtests of the WMS during each of the three test sessions. While initial learning on Verbal Paired Associate materials was affected at the time of the second test session (12th week of zonisamide therapy) $(p<0.05)$, visualgraphic learning was not. Orientation for personal and current information, as well as to time and place, was also unaffected. Memory for passages of information that were read aloud to the patients (Logical Memory) also showed decline $(\mathrm{p}<0.01)$, but alphabet recitation did not. In contrast to observations of immediate recall tasks, where verbal learning alone showed a decline, visual-graphic as well as verbal performance showed a decline when the patient's recall was delayed for $30 \mathrm{~min}$ after initial learning.

Statistically significant changes in overall $\mathrm{MQ}$ occurred between baseline testing and the test session performed after 12 weeks of zonisamide therapy. On the other hand, well-rehearsed and "crystallized" intellectual abilities, such as those reflected in the Vocabulary subtest of the WAIS-R, remained unaffected. Attention and psychomotor 


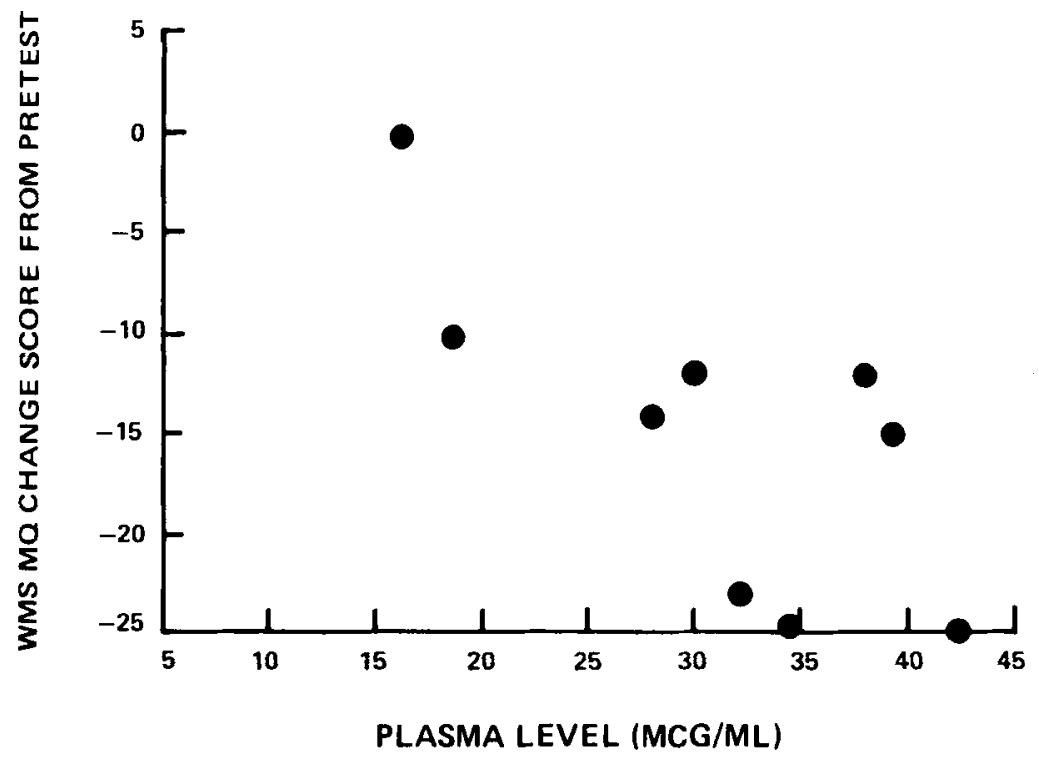

FIG. 4. Scatter diagram of change in memory quotient (MQ) and corresponding plasma level of zonisamide for each patient in session 2. WMC, Wechsler Memory Scale.

and motor coordination tasks also showed no effect, as reflected in tasks such as simple reaction time and time to complete a grooved peg board task. Perceptual orientation, as measured by the Rod-and-Frame test, and complex motor-symbolic learning, as reflected in the Digit Symbol subtest of the WAIS-R, remained relatively stable across test sessions.

It should be mentioned that all patients were judged to be free of seizure activity for at least $24 \mathrm{~h}$ prior to testing. Also, seizure frequency was in all cases reduced at the time of test sessions 2 and 3 in comparison with baseline measurements. For further information concerning seizure type and other clinical details, see our earlier report (Sackellares et al., 1985).

\section{DISCUSSION}

The results of this pilot work suggest that zonisamide, in doses within the range tolerated clinically, affects specific types of cognitive abilities but not

TABLE 3. Performance on behavioral tasks for each test session

\begin{tabular}{|c|c|c|c|c|c|}
\hline Name and task & $\begin{array}{c}\text { Session } 1 \\
{[\text { mean (SD)] }}\end{array}$ & $\begin{array}{c}\text { Session } 2 \\
{[\text { mean }(S D)]}\end{array}$ & $\begin{array}{l}t \text { test }^{a} \\
(2 \text { to } 1)\end{array}$ & $\begin{array}{c}\text { Session } 3 \\
{[\text { mean }(\mathrm{SD})]}\end{array}$ & $\begin{array}{l}t \text { test }^{a} \\
(3 \text { to } 1)\end{array}$ \\
\hline \multicolumn{6}{|l|}{ WAIS-R: } \\
\hline Digit Symbol & $7.6 \quad(2.4)$ & $7.3 \quad(2.3)$ & NS & (2.6) & NS \\
\hline Vocabulary & $8.3 \quad(1.9)$ & $8.2 \quad(1.7)$ & NS & $(2.1)$ & NS \\
\hline Arithmetic & $9.3 \quad(3.5)$ & $7.8 \quad(1.9)$ & NS $[0.06]$ & $(2.3)$ & NS \\
\hline Rod-and-Frame & $7.6 \quad(8.6)$ & $10.1(12.3)$ & NS & $9.6 \quad(11.4)$ & NS \\
\hline \multicolumn{6}{|l|}{ Reaction Time: } \\
\hline Simple & $309.6(79.7)$ & $320.9(88.9)$ & NS & $322.7(105.8)$ & NS \\
\hline Choice & $404.7(84.8)$ & $426.4(74.2)$ & NS & $438.8(137.6)$ & NS \\
\hline Finger Tapping & $45.1 \quad(6.9)$ & $43.9 \quad(6.4)$ & NS & $(5.4)$ & NS \\
\hline Grip Strength & $32.4(10.9)$ & $34.4(10.1)$ & NS & $33.9(10.6)$ & NS \\
\hline Peg Board & $89.9(19.2)$ & $97.8(44.9)$ & NS & $89.8 \quad(29.9)$ & NS \\
\hline \multicolumn{6}{|l|}{ Wechsler Memory Scale: } \\
\hline MQ & $101.0 \quad(9.8)$ & $86.4 \quad(9.6)$ & $<0.001$ & $96.6 \quad(10.4)$ & NS \\
\hline Logical Memory & $9.4 \quad(2.2)$ & $7.7 \quad(1.4)$ & $<0.01$ & $8.8 \quad(2.6)$ & NS \\
\hline Visual Reproduction & $9.5 \quad(1.7)$ & $8.3 \quad(3.1)$ & NS & (1.8) & NS \\
\hline Verbal Paired Associates & $14.2 \quad(4.9)$ & $11.2 \quad(3.7)$ & $<0.05$ & (4.2) & NS \\
\hline \multicolumn{6}{|l|}{ Logical Memory } \\
\hline (delayed recall) & $7.1 \quad(2.1)$ & $5.0 \quad(1.9)$ & $<0.001$ & (2.6) & NS \\
\hline $\begin{array}{l}\text { Visual Reproduction } \\
\text { (delayed recall) }\end{array}$ & $8.7 \quad(2.9)$ & $5.9 \quad(4.1)$ & $<0.05$ & (3.1) & NS \\
\hline $\begin{array}{l}\text { Verbal Paired Associates } \\
\text { (delayed recall) }\end{array}$ & $7.3 \quad(2.5)$ & $6.3 \quad(2.1)$ & NS & (2.1) & NS \\
\hline
\end{tabular}

${ }^{a}$ MQ, memory quotient; NS, not significant.

A $t$ test for correlated samples was used for all comparisons and computed on a microcomputer with STATFAST 512.2. 
others. These effects appear to be related linearly to plasma drug concentration. Acquisition of verbal material (verbal learning) was impaired, but learning of visual-graphic stimuli was unaffected by the drug. Previously learned material, such as vocabulary, and well-rehearsed acts (alphabet recitation) were unaffected, as was psychomotor ability (drawing of geometric shapes). The capacity to report the responses to test items was preserved in all cases. Immediate concentration and attention as well as orientation to personal and external environment remained intact. After a delay of $30 \mathrm{~min}$ from initial practice, patients showed difficulty in recall of both verbal and visual-graphic task stimuli. This finding suggests that the effect on memory function is mechanistically distinct from the effect on initial acquisition of information, since only initial acquisition of verbal items was impaired.

The fact that impaired function was modality specific rather than global is evidence against a global depression of cerebral function such as lethargy or motivation. Any hypothesis proposed to explain these results must account for the verbal learning and memory-specific attributes of the observed effects and the lack of impact on more general behaviors such as attention and motivation.

The differences observed between test sessions 2 and 3 suggest the development of tolerance to zonisamide. However, the time course for the reduced effect of zonisamide on neuropsychological function is unusually slow for the development of drug tolerance. Because of the small number of observations in the present work, further study will be required to evaluate the hypothesis that improvement in behavioral function is a result of drug tolerance. If tolerance to the adverse cognitive effects of zonisamide is confirmed, this finding would suggest that these adverse effects may be avoided by initiating treatment with lower doses. Higher doses may be used after tolerance to cognitive side effects develops.

It is significant that patients and their families were unaware of a decline in ability in spite of relatively large changes in memory and learning capacity. Since measurable adverse effects on cognition may occur in the absence of clinical symptoms, patients receiving zonisamide should be monitored for changes in mental status, especially when plasma drug levels are $>30 \mu \mathrm{g} / \mathrm{ml}$. A formal psychometric examination with a test such as the WMS would be useful for early identification of cognitive impairment. Formal psychometric testing may be helpful in distinguishing adverse effects of zonisamide from other causes of impaired mentation such as drowsiness, lethargy, or depression.
If comprehensive neuropsychological testing is not available, special attention should be paid to changes in the specific areas of mental ability such as learning and memory.

Traditionally, the upper limit of the usual "therapeutic range" of plasma level for an antiepileptic drug is determined by the level at which clinical signs or symptoms of adverse effects are observed. The results of this study suggest that, for some antiepileptic drugs, significant adverse effects may occur which are not detectable by the patient or by the bedside neurological examination. For drugs such as zonisamide, the upper limit of the therapeutic range may be defined more precisely as the plasma level at which measurable changes in cognitive abilities are observed. In the present work. measurable cognitive effects surfaced at plasma levels above $30 \mu \mathrm{g} / \mathrm{ml}$. Anticonvulsant effects were noted to occur below this level (see Sackellares et al., 1985). Although earlier animal studies had indicated that toxicity would occur well above $30 \mu \mathrm{g} / \mathrm{ml}$ (Masuda et al., 1979), there are individual differences in response that need further elucidation. Cognitive as well as clinical side effects have been observed at plasma drug concentrations below this point (Sackellares et al., 1985).

The use of objective, quantifiable, and standardized psychometric techniques in the present work allowed for a detailed description of the kinds of cognitive abilities that changed as a function of plasma concentrations of zonisamide. In large part, the clarity of these results in the presence of a relatively small number of observations is due to the homogeneity of baseline scores that were earned by the patients in the study. Nevertheless, the results demonstrate the usefulness of psychometrics in application to research in the development of new medications.

The generalizability of these findings is limited by a number of considerations in addition to those already mentioned. Conclusions must be tentative since the size of the study was small. Patients were taking medications other than zonisamide and these may have potentiated the effects on cognition. No control group was employed. In short, these results seem clearly to reveal a strong relationship between drug plasma concentrations of zonisamide and specific cognitive side effects. Any conclusions about absolute cause and effect, however, will require further study.

Acknowledgment: We wish to thank Kristine AasvedHoyt, R.N., M.S., Nancy Kuzminski, B.A., Shirley Lehtinen, M.A., John McLean, Ph.D., and Betty Terrazas for their help. This study was supported by grants from 
the Warner-Lambert Company and the University of Michigan Clinical Research Center, grant number M01RR00042.

\section{REFERENCES}

Boll TJ. The Halstead-Reitan neuropsychological battery. In: Filskov S, Boll TJ, eds. Handbook of clinical neuropsychology. New York: Wiley, 1981:577-607.

Dreifuss FE, Penry $\rfloor K$, Bancaud J, Henricksen O, Rubio-Donnadieu F, Seins M. Proposal for revised clinical and electroencephalographic classification of epileptic seizures. Epilepsia 1981:22:489-501.

Giordani B, Sackellares JC, Miller S, Berent S. Sutula T, Seidenberg M, Boll TJ, O'Leary D, Dreifuss FE. Improvement in neuropsychological performance in patients with refractory seizures following intensive diagnostic and therapeutic intervention. Neurology (NY) 1983;33:489-93

Ito T, Hori M, Masuda Y, Yoshida K, Shimizu M. 3-Sulfamoyl methyl-1,2-benzisoxazole, a new type of anticonvulsant drug: electroencephalographic profile. Arzneimittelforsch 1980;30:603-9.

Kamei C, Oka M, Masuda Y, Yoshida K, Shimizu M. Effects of 3-sulfamoylmethyl-1,2-benzisoxazole (AD-810) and some antiepileptics on the kindled seizures in the neocortex, hippocampus and amygdala in rats. Arch Int Pharmacodyn $1981 ; 249: 164-76$

Macleod CM, Dekaban AS, Hunt E. Memory impairment in epileptic patients: selective effects of phenobarbitone concentration. Science 1978;202:1102-4.

Matarazzo JD, Wiens AH, Matarazzo RG, Goldstein SG. Psychometric and clinical test-retest reliability of the Halstead Impairment Index in a sample of healthy, young, normal men. J Nerv Ment Dis 1974;158:37-49.

Masuda Y, Karasawa T, Shiraishi Y, Hori M, Yoshida K, Shimizu M. 3-Sulfamoylmethyl-1,2-benzisoxazole, a new type of anticonvulsant drug. Arzneimittelforsch 1980;30:477-83.

Masuda Y, Utsui Y, Shiraishi Y, Karasawa T, Yoshida K, Shimizu M. Relationship between plasma concentrations of diphenylhydantoin, phenobarbital, carbamazepine, and 3-sulfamoylmethyl-1,2-benzisoxazole (AD-810), a new anticonvulsant agent, and their anticonvulsant or neurotoxic effects in experimental animals. Epilepsia 1979;20:623-33.

Matthews CG, Harley JP. Cognitive and motor-sensory performance in toxic and non-toxic epileptic subjects. Neurology (NY) 1975;25:184-8

Sackellares JC, Donofrio PD, Wagner JG, Abou-Khalil B, Berent S, Aasved-Hoyt K. Pilot study of zonisamide (1,2benzisoxazole-3-methanesulfonamide) in patients with refractory partial seizures. Epilepsia 1985;26:206-11.

Thompson P, Trimble MR. Comparative effects of anticonvulsant drugs on the memory test performance of non-epileptic subjects. Acta Neurol Scand 1980;62(suppl):79.

Trimble MR. Effects of anticonvulsant drugs on cognitive function and behavior. In: Essman WB, Vakelli L, eds. Current developments in psychopharmacology. New York: Spectrum, 1981:65-91.
Wagner JG, Sackellares JC, Donofrio PD, Berent S, Sakmar E Nonlinear pharmacokinetics of $\mathrm{Cl}-912$ in adult epileptic patients. Ther Drug Monit 1984;6:277-83.

Wechsler DA. Standardized memory scale for clinical use. $J$ Psychol 1945;19:95-7.

Wechsler DA. Wechsler adult intelligence scale-revised (WAIS-R) manual. New York: The Psychological Corporation, 1981.

Witkin HA, Dyk KB, Fateson HF, Goodenough DR, Karp SA. Psychological differentiation. New York: Wiley, 1974.

Wilensky AJ, Friel PN, Ojeman LM, Dodrill CB, McCormick KB, Levy RH. Zonisamide in epilepsy: a pilot study. Epilepsia $1985 ; 26: 212-20$.

\section{RESUMEN}

En un estudio piloto realizado para valorar la eficacia de la zonisamida (1,2-Bencisoxazol-metanosulfonamida [CI-912]), un nuevo compuesto anticonvulsivo, se han evaluado unos 9 pacientes con ataques parciales refractarios al tratamiento. Se determinó la capacidad cognitiva anterior al tratamiento y se repitió 12 y 24 semanas después del tratamiento con zonisamida. Con concentraciones plasmáticas mínimas estables per encima de $30 \mathrm{mcg} / \mathrm{ml}$, la zonisamida afectó las funciones cognitives específicas tales como la adquisición y consolidación de nueva información. El material aprendido previamente, tal como el vocabulario, y las funciones psicomotoras no se afectaron. El aprendizaje verbal se modificó mientras que el aprendizaje visuo-perfectivo no se modificó. Estos efectos cognitivos se observaron en ausencia de los habituales signos y síntomas clínicos de toxicidad. Se encontró una relación lineal entre la alteración de las posibilidades cognitivas y la concentración plasmática mínima $(r=-0.73, p<0.05)$. Estos hallazgos también sugieren el desarrollo de una tolerancia a los efectos cognitivos adversos

(A. Portera-Sánchez, Madrid)

\section{ZUSAMMENFASSUNG}

9 Patienten mit rezidivierenden Partial-Anfällen wurden in einer Pilotstudie mit einer neuen antiepileptischen Substanz: Zonisamide untersucht. Die kognitiven Funktionen wurden vor der Behandlung mit Zonisamide geprüft und nach 12 und 24 Therapiewochen mit Zonisamide wiederholt. Bei einem Mindestplasmaspiegel von $30 \mathrm{mcg} / \mathrm{ml}$ schien Zonisamide spezifische kognitive Fähigkeiten wie Aufnahme und Speicherung neuer Informationen $\mathrm{zu}$ beeinträchtigen. Vorher gelernte Inhalte wie sprachliche und psychomotorische Fertigkeiten wurden nicht beeinflußt. Verbales Lernen war ebenfalls betroffen, während visuell, perzeptives Lernen nicht verschlechtert war. Diese Beeinträchtigung kognitiver Funktionen wurde bei fehlenden klinischen Intoxikationszeichen beobachtet. Eine lineare Beziehung zwischen Verschlechterung kognitiver Fähigkeiten und Mindest-Plasmaspiegel konnte hergestellt werden $(\mathrm{r}=-0,73 ; \mathrm{p}$ $<0,05$ ). Allerdings lassen die Ergebnisse auch auf eine Gewöhnung an diese unerwünschten Nebenwirkungen schließen.

(C. G. Lipinski, Heidelberg/Neckargemünd) 